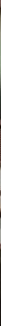

\title{
APLICAÇÃO DE TÉCNICAS COMPENSATÓRIAS DE DRENAGEM NA REQUALIFICAÇÃO DE ÁREAS VERDES URBANAS EM GUARULHOS - SP
}

Application of compensatory drainage techniques in the rehabilitation of urban green areas in Guarulhos - SP

Aplicación de técnicas de drenaje de compensación en la rehabilitación de las zonas verdes urbanas en Guarulhos - SP

Alinne Prado de Oliveira Arquiteta e Discente em Mestrado - Programa de Pós-Graduação em Engenharia Urbana, UFSCar, Brasil. alinne.pradoliveira@gmail.com.br

Ademir Paceli Barbassa

Engenheiro e Professor Doutor, UFSCar, Brasil. barbassa@ufscar.br

Luciana Márcia Gonçalves

Arquiteta e Professora Doutora, UFSCar, Brasil. lucianamg@ufscar.br 


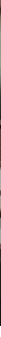

RESUMO

Técnicas compensatórias de drenagem consistem em tecnologias de baixa complexidade construtiva e baixo impacto ambiental, que visam otimizar a infiltração e/ou reter água de chuva, reduzindo o escoamento superficial direto e os altos investimentos em dispositivos hidráulicos da drenagem tradicional. Por tais características, estas técnicas foram utilizadas nos projetos paisagísticos realizados nos últimos anos em áreas verdes na cidade de Guarulhos - SP com o intuito de solucionar a microdrenagem dos projetos, de valorizar a presença da água no meio urbano, bem como trazer melhorias nas condições ambientais (solo, microclima, maior diversidade de espécies de flora e fauna). As técnicas compensatórias utilizadas foram: pavimentos permeáveis, valas de infiltração, bacias e valetas, avaliadas neste trabalho quanto à funcionalidade hidrológica e inserção urbana. Por meio dos projetos de requalificação urbana realizados em áreas verdes de centros urbanos, tal qual a experiência de Guarulhos, é possível identificar vantagens, potencialidades e limitações do uso de técnicas compensatórias em áreas urbanas consolidadas e necessitadas de melhorias urbanísticas, ambientais e, principalmente, na drenagem.

PALAVRAS-CHAVE: Técnicas compensatórias. Drenagem urbana. Requalificação de áreas verdes.

\section{ABSTRACT}

Compensatory techniques drainage consist of low constructive complexity and low environmental impact technologies, which aim to optimize the infiltration and rainwater retention, reducing the direct runoff and high investments in hydraulic devices of traditional drainage. For such characteristics, these techniques were used in landscaping projects undertaken in recent years in green areas in the city of Guarulhos - SP in order to resolve the minor drainage projects, to value the presence of water in the urban environment as well as bring improvements in conditions environmental (soil, microclimate, greater diversity of flora and fauna). Compensatory techniques used were: permeable pavements, swales, basins and trenches, evaluated in this work as the hydrologic feature and urban integration. Through the urban renewal projects carried out in green areas of urban centers, like the Guarulhos experience, you can identify advantages, potentials and limitations of using compensatory techniques in consolidated and needy urban areas of urban planning, environmental improvements and, especially, drainage.

KEYWORDS: Compensatory techniques. Urban drainage. Requalification of green areas.

\section{RESUMEN}

Técnicas compensatorias de drenaje consisten en baja complejidad constructiva y tecnologías de bajo impacto ambiental, cuyo objetivo es optimizar la infiltración de agua de lluvia y la retención, la reducción de la escorrentía directa y altas inversiones en dispositivos hidráulicos de drenaje tradicional. Para tales características, estas técnicas se utilizan en proyectos de paisajismo llevadas a cabo en los últimos años en las zonas verdes en la ciudad de Guarulhos - SP con el fin de resolver los proyectos de drenaje de menor importancia, para valorar la presencia de agua en el medio urbano, así como aportar mejoras en las condiciones de medio ambiente (suelo, microclima, mayor diversidad de flora y fauna). técnicas compensatorias utilizadas fueron: pavimentos permeables, cunetas, zanjas, cuencas y evaluados en este trabajo como la función hidrológica y la integración urbana. A través de los proyectos de renovación urbana llevadas a cabo en las zonas verdes de los centros urbanos, como la experiencia de Guarulhos, puede identificar ventajas, potencialidades y limitaciones de la utilización de técnicas compensatorias en las zonas urbanas consolidadas y necesitadas de la planificación urbana, la mejora del medio ambiente y, sobre todo, drenaje.

PALABRAS CLAVE: Técnicas compensatorias. Drenaje urbano. Recalificación de zonas verdes. 


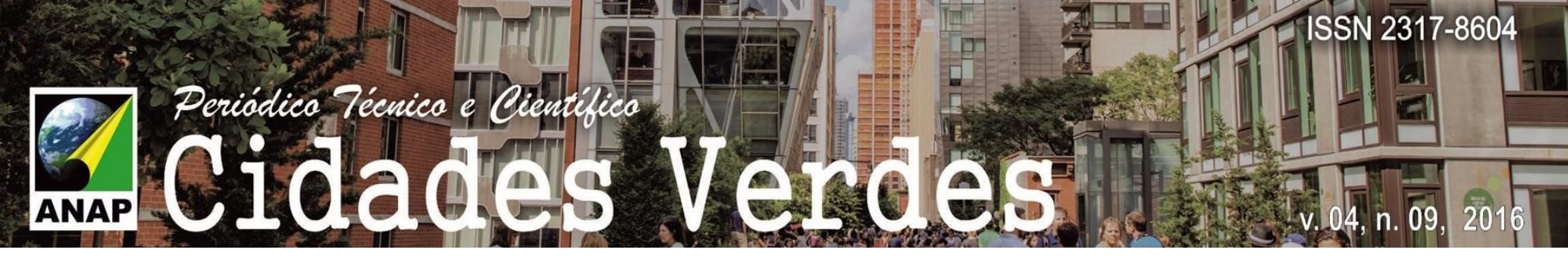

\section{INTRODUÇÃO}

A urbanização das cidades brasileiras, baseada no modelo higienista da drenagem tradicional, pratica a retirada da cobertura vegetal e a impermeabilização do solo urbano, dos canais e condutos da rede de águas pluviais, a fim de evacuar rapidamente a água de chuva, aumentando-se a velocidade e a quantidade do escoamento superficial. Esse modelo da engenharia reflete a idéia pré-concebida de que, a boa drenagem é aquela que permite escoar a água de chuva rapidamente através de córregos e canais, retirando-a do contato com o meio urbano. No entanto, tal conceito tem se mostrado insuficiente e ineficiente. Neste trabalho considera-se a melhor drenagem como aquela que drena o escoamento sem produzir impactos nem no local, nem a jusante do curso d’água (TUCCl et al., 1995).

Os recorrentes problemas de enchentes nas áreas urbanas são frutos deste modelo em que as ações antrópicas ocasionam alterações no ciclo hidrológico, cujas consequências têm produzido custos elevados para sociedade e causam prejuízos à vida urbana, porém, passíveis de serem minimizados.

Algumas experiências internacionais têm avançado no manejo sustentável das águas pluviais, buscando prevenir e reduzir os efeitos da urbanização na drenagem urbana com uma metodologia que aborda os impactos de uma forma integrada, desde a concepção do projeto (TUCCl, 2007), com medidas não estruturais e técnicas compensatórias estruturais: mais econômicas, de menor impacto ambiental, e que auxiliam no desenvolvimento sustentável das áreas urbanas (BAPTISTA et al., 2011).

É dentro deste contexto que a drenagem das áreas urbanas vem desempenhando um papel cada vez mais relevante dentro do planejamento urbano e das obras de infraestrutura das cidades, pois é ela quem "administra" o impacto das águas de chuva no meio urbano, fundamentais para o bom desempenho do ciclo hidrológico nas cidades.

A cidade de Guarulhos faz parte da Região Metropolitana de São Paulo e é hoje a segunda cidade mais populosa do Estado (IBGE, 2016). Como a maior parte dos centros urbanos do país, possui diversos desafios sociais, ambientais, de infraestrutura urbana e, entre eles, de drenagem urbana a serem solucionados. A cidade possui áreas acidentadas e com maior cobertura vegetal numa contínua faixa ao Norte, que alimentam os diversos cursos $d$ água que percorrem os terrenos com relevos mais suavizados, contendo extensas planícies de inundação, onde se encontram as áreas mais urbanizadas e onde ocorrem, conseqüentemente, as enchentes (Prefeitura de Guarulhos, 2008).

Voltados à questão ambiental, alguns projetos de implantação de novas áreas verdes e de lazer, bem como intervenções paisagísticas para requalificação de áreas verdes existentes realizados pela Prefeitura de Guarulhos apresentaram soluções de drenagem em microescala (técnicas compensatórias), como alternativas para reduzir o escoamento superficial destas áreas para a rede de águas pluviais existentes.

Os dispositivos destacados neste trabalho avaliam as experiências em técnicas compensatórias de drenagem realizadas pela administração pública da cidade de Guarulhos, quanto aos seus benefícios e prejuízos hidrológicos e quanto à integração à paisagem urbana. 


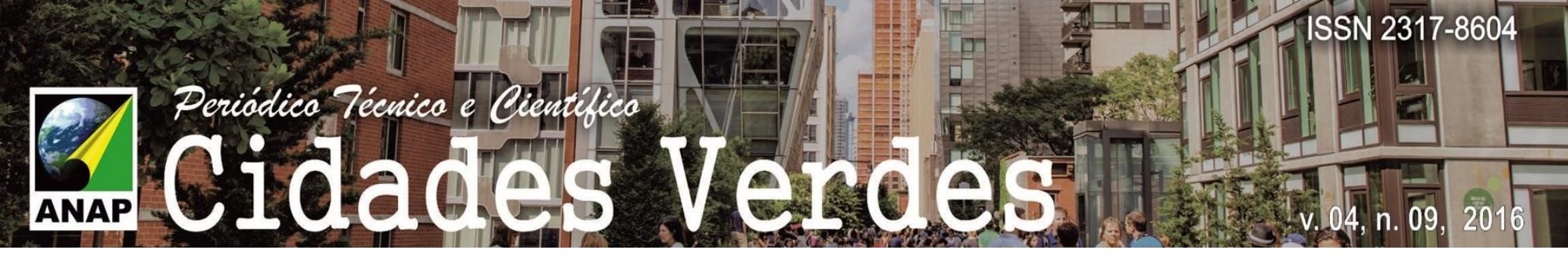

dependem de construções e são mais caras, tais como canalizações, diques com bombeamentos, reversões e barragens, entre outras. Com isso, o poder público passa a investir uma parte significativa do seu orçamento para sanar os problemas de apenas uma parcela da cidade que sofre devido à negligência da ocupação do solo (TUCCl et al., 1995).

\subsection{AS TÉCNICAS COMPENSATÓRIAS}

Para compensar parte dos efeitos negativos da urbanização sobre os processos hidrológicos, as técnicas compensatórias (TCs) ou técnicas alternativas de drenagem baseiam-se em novos conceitos, a partir dos anos 70, sobretudo na Europa e na América do Norte, com benefícios para a qualidade de vida e a preservação ambiental nos espaços urbanos. Estas alternativas diferem dos dispositivos clássicos de drenagem comumente utilizados nas cidades, pois consideram os impactos da urbanização de forma global, levando em consideração a bacia de contribuição como base de estudo.

Segundo Baptista et al.(2011), o emprego das TCs na drenagem urbana possibilita a continuidade do processo de crescimento urbano sem novos grandes investimentos em infraestrutura de drenagem, pois possibilitam a modulação desse sistema em função do crescimento e tratamento combinado das questões de drenagem pluvial com outras questões urbanísticas. Quando bem concebidas, as TCs contribuem efetivamente para a melhoria da qualidade de vida nas cidades, como a recuperação e a preservação do meio ambiente com a redução das cargas de poluição de origem pluvial. O uso de TCs trata-se de procedimento favorável às condições necessárias para o desenvolvimento sustentável em áreas urbanas.

As TCs consistem em combinações de soluções que facilitam a infiltração de águas pluviais e o aumento da permanência do armazenamento da água reduzindo a vazão de pico e escoamentos superficiais. Podem-se destacar as seguintes TCs que acumulam tais funcionalidades: bacias de detenção, planos de infiltração, pavimentos porosos, poços, trincheiras, valas gramadas, valetas e tratamentos de fundo de vale com armazenamentos temporários e delimitação de áreas de preservação permanente.

Verifica-se, em exemplos apresentados por Baptista et al.(2011), que apesar das TCs objetivarem principalmente a contenção das águas de chuva, é essencial que estes dispositivos se integrem ao espaço urbano. Assim, as boas práticas de manejo de águas pluviais devem ser abordadas de maneira multidisciplinar, com a participação de diversos profissionais, bem como contar com o envolvimento da população local para aceitação e uso adequado das estruturas alternativas de drenagem.

Neste artigo, serão apresentadas as TCs utilizadas em projetos paisagísticos de áreas verdes urbanas praticados em Guarulhos com o intuito de verificar sua funcionalidade hidrológica e inserção urbana, a fim de se identificar as potencialidades da aplicação das técnicas em substituição ao sistema convencional de drenagem urbana. 


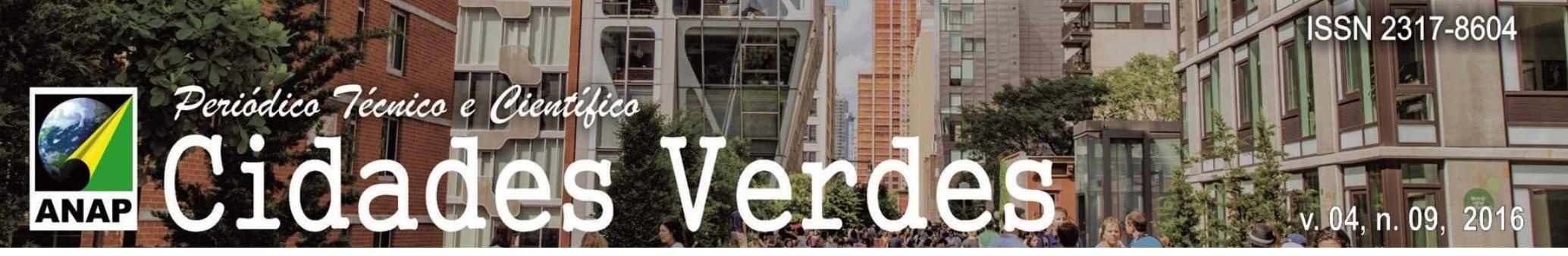

de solucionar a microdrenagem local, ou seja, não direcionar a água de chuva diretamente para o sistema de drenagem, mas sim, absorver/reter a água pluvial ali captada para o solo, propiciando, inclusive, melhor desenvolvimento das espécies vegetais ali plantadas dependendo menos de irrigação.

As TCs analisadas foram realizadas em áreas verdes, parques, jardins públicos e áreas de lazer de maneira empírica, baseadas na experiência pessoal dos profissionais envolvidos, sem dimensionamento prévio para definição da técnica a ser executada no local e ainda carecem de avaliação de sua eficiência pós-implantação.

1 -Valas de infiltração (VI) de águas pluviais provenientes da drenagem do campo de futebol.

Figura 2a e b. Trecho da vala de infiltração junto a campo de futebol. Úmida e seca.

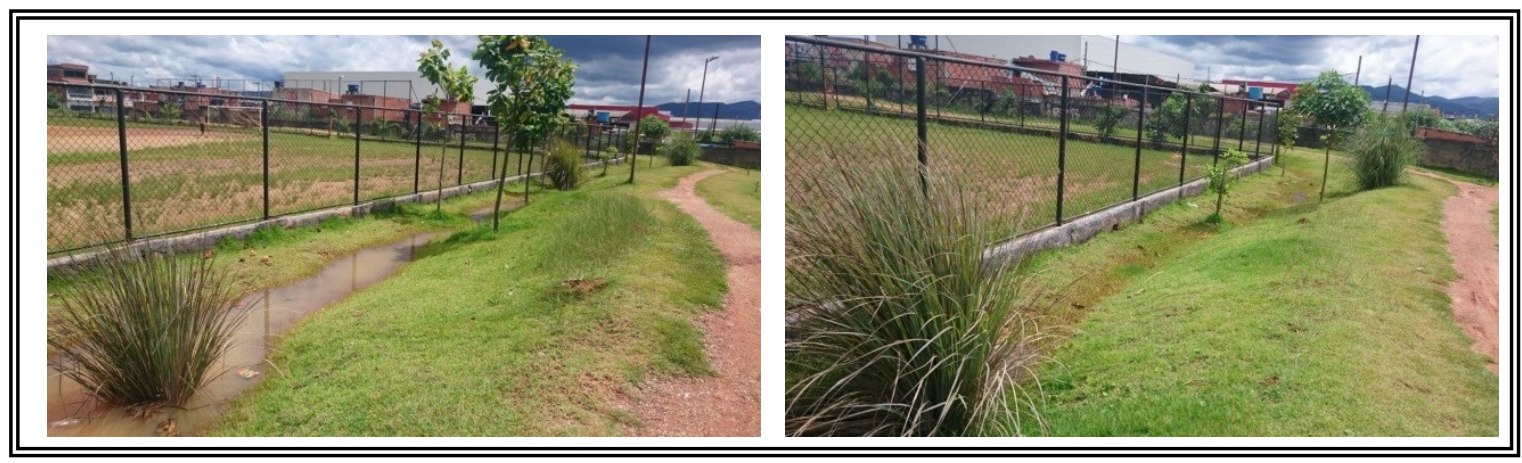

Fonte: AUTORA, 2016.

Projeto: VI CampoCaxias - Vala de infiltração em área de lazer do campo de futebol do Caxias. Endereço: Rua Marinópolis, Jd. Presidente Dutra, Guarulhos - SP.

Área total do projeto: $15.000 \mathrm{~m}^{2}$

Descrição:

As valas de infiltração foram criadas ao longo das bordas de todo o campo de futebol, que possui mureta de aproximadamente $20 \mathrm{~cm}$ de bloco de concreto que sustenta o alambrado e que acabam impedindo o escoamento de água direto para as laterais. Existem aberturas para saída de água de chuva ao longo das muretas, alguns feitos com tubos em PVC e outros improvisados com buracos feitos na própria alvenaria de blocos.

Com técnicas de paisagismo, foram escavadas com retroescavadeira as valas de infiltração em todo o perímetro do campo que, após atingirem profundidade de cerca de $80 \mathrm{~cm}$ (variável), devido a inclinação necessária para escoamento superficial, foi ainda "modelada" manualmente com enxada, deixando as valas com o fundo e as laterais arredondadas, buscando um aspecto natural e orgânico na paisagem. Podemos observar que as valas não são rigidamente lineares, mas foram desenhadas em curvas que "serpenteiam" o terreno, bem como não possuem a mesma largura ao longo do trecho como um canal construído, mas possui alargamentos de até aproximadamente 3 metros em alguns pontos, criando pequenas bacias (todas interligadas nos pontos baixos) com jardins de plantas palustres que retém por mais tempo a água de chuva, voltando a escoar para a vala mais a frente. $O$ talude que separa a vala do passeio, gerado com a diferença de nível necessária para execução e funcionamento da vala, também foi modelado manualmente com alturas e larguras diferentes, fazendo com que a vala se pareça com um pequeno vale sinuoso entre morrotes de terra baixos e gramados, atingindo, no máximo, $1.5 \mathrm{~m}$ de altura. 


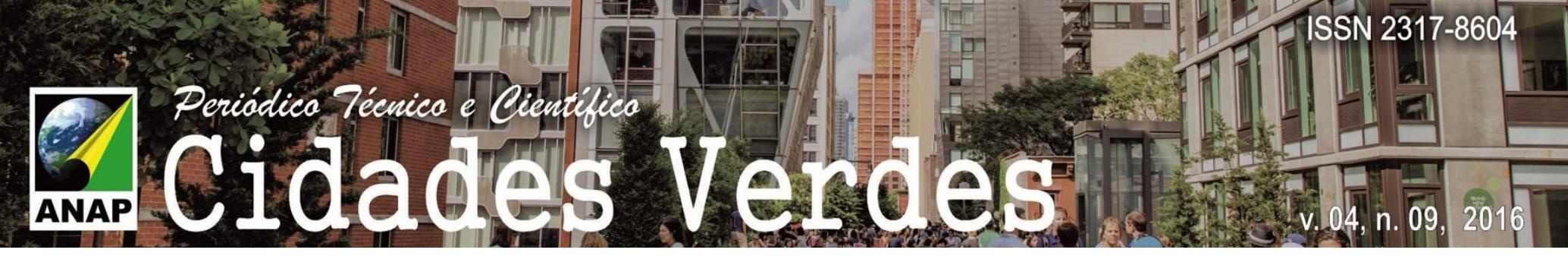

Área total de projeto: $1.500 \mathrm{~m}^{2}$

Descrição:

Esta TC mista consiste no conjunto entre poços abertos e valas de infiltração, para redução da velocidade e condução da água de chuva com o objetivo de evitar erosões e outros prejuízos que a intensidade da chuva pode ocasionar.

Trata-se de uma área cercada para cães que está sendo executada na encosta do principal parque da cidade, o Bosque Maia. É um terreno em aclive que recebe água de chuva da rua por meio de sarjeta de concreto armado, ou seja, por canais longitudinais que coletam e conduzem as águas superficiais da faixa pavimentada, até a rede de drenagem ou outro ponto de saída.

No intuito de reduzir as águas pluviais destinadas à rede pluvial pública ou até desconectar da rede, foram previstos dispositivos hidráulicos para captar, reduzir a velocidade e disciplinar a água de chuva que chega até a área de implantação do novo equipamento público. Para solucionar a microdrenagem local, foram implantadas TCs mistas com DDIs de água de chuva feitos com o uso de materiais inertes reaproveitados como resíduos da construção civil, caixas d água furadas, pedaços de tubo em PVC e peças pré-moldadas em argamassa armada (material desmontado de estrutura predial de antiga escola demolida na cidade).

Foi verificado, conforme apresentado em Figura 4a, que a água proveniente da sarjeta foi captada por uma seção de tubo de PVC cortado tipo meia-cana sob a laje da calçada e lançada a um poço feito com uma caixa d'água reaproveitada de 5.000 com fundo perfurado preenchido com rachão (brita superior a $100 \mathrm{~mm}$ ) para desacelerar a água de chuva. Após a "quebra" do impacto da chegada da água, esta escoa por uma das laterais do fundo deste poço, onde foi escavada uma valeta superficial com diversos resíduos de construção civil em seu fundo e lateral, que conduz a água mais lentamente devido à presença desses resíduos permitindo sua infiltração, dependendo da sua velocidade. A valeta conduz a água até outro poço feito com caixa d água reaproveitada enterrada no solo, também com fundo aberto com rachão para infiltração e que, quando cheio, extravasa por um tubo de saída na parte superior da caixa. Este tubo, após atravessar por baixo (enterrado) um trecho de calçada, conduz a água de chuva até a outra valeta escavada superficialmente e aberta no solo, esta atravessando também outro trecho de calçada em laje suspensa, propiciando a passagem livre da água. Por fim, o exutório desta água é uma valeta escavada a céu aberto que deságua num pequeno lago construído a jusante, na área do parque.

Além destes dispositivos construídos para drenagem, o projeto também faz uso de pisos permeáveis no local. Os platôs foram feitos com pedrisco e as calçadas foram executadas em concreto permeável, permitindo infiltração da água de chuva. 


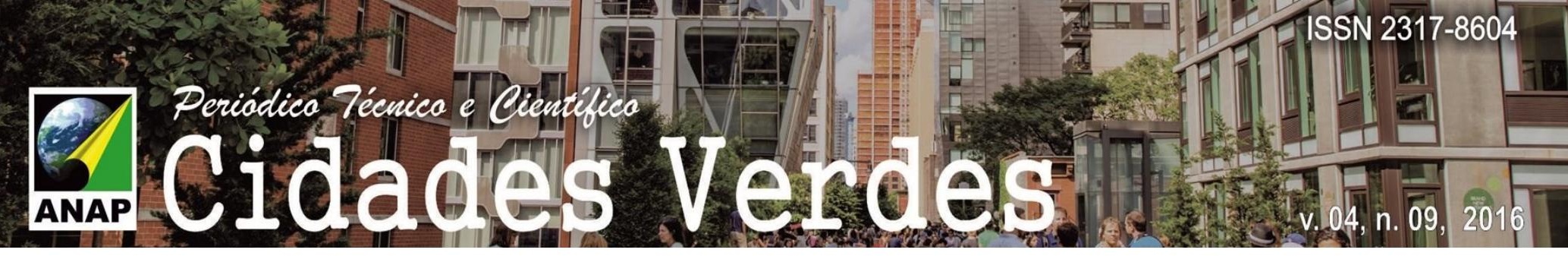

Figura 5a e b: Foto da calçada em concreto permeável com sub-base de resíduos da construção civil e corte esquemático dos DDI_Parcão.

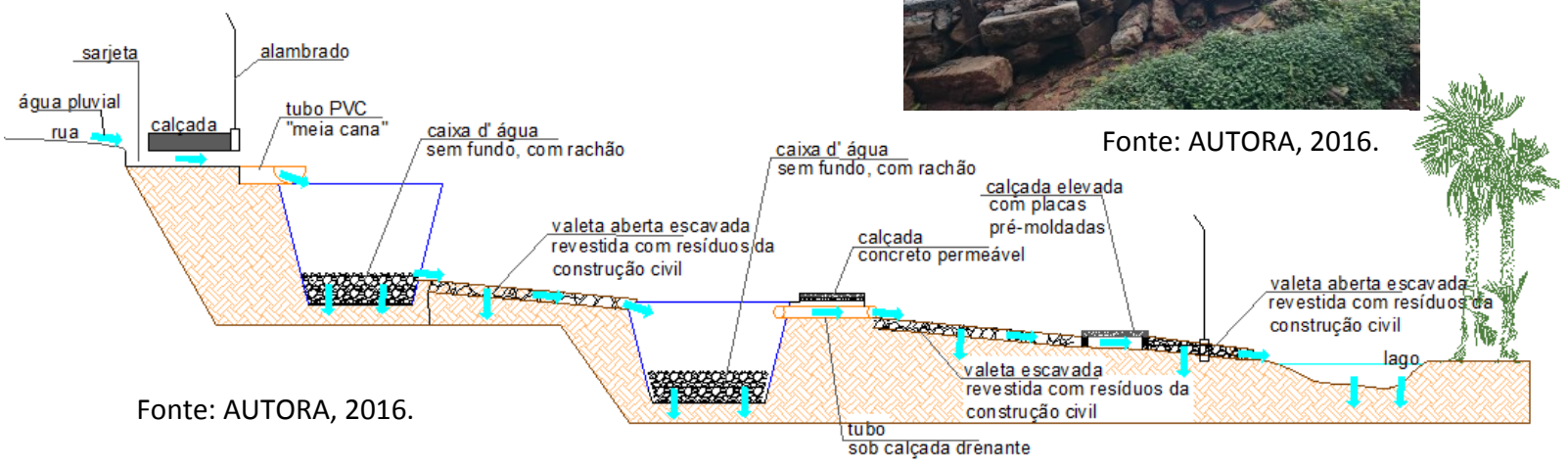

As calçadas são em níveis mais altos que os dos canteiros de jardins elevadas por resíduos grandes da construção civil, conforme apresentado em Figura 5a, empilhados e travados, proporcionando assim uma sub-base do piso de concreto drenante (de $7 \mathrm{~cm}$ de espessura) também permeável, que permite a absorção e a condução da água ao solo e às plantas.

3 - TCs integradas de pavimentos permeáveis e detenção de água de mina (afloramento) e água de chuva de viaduto.

Figura 6a,b e c: Fotos do projeto de paisagismo sob Viaduto com espelhos d água para detenção.

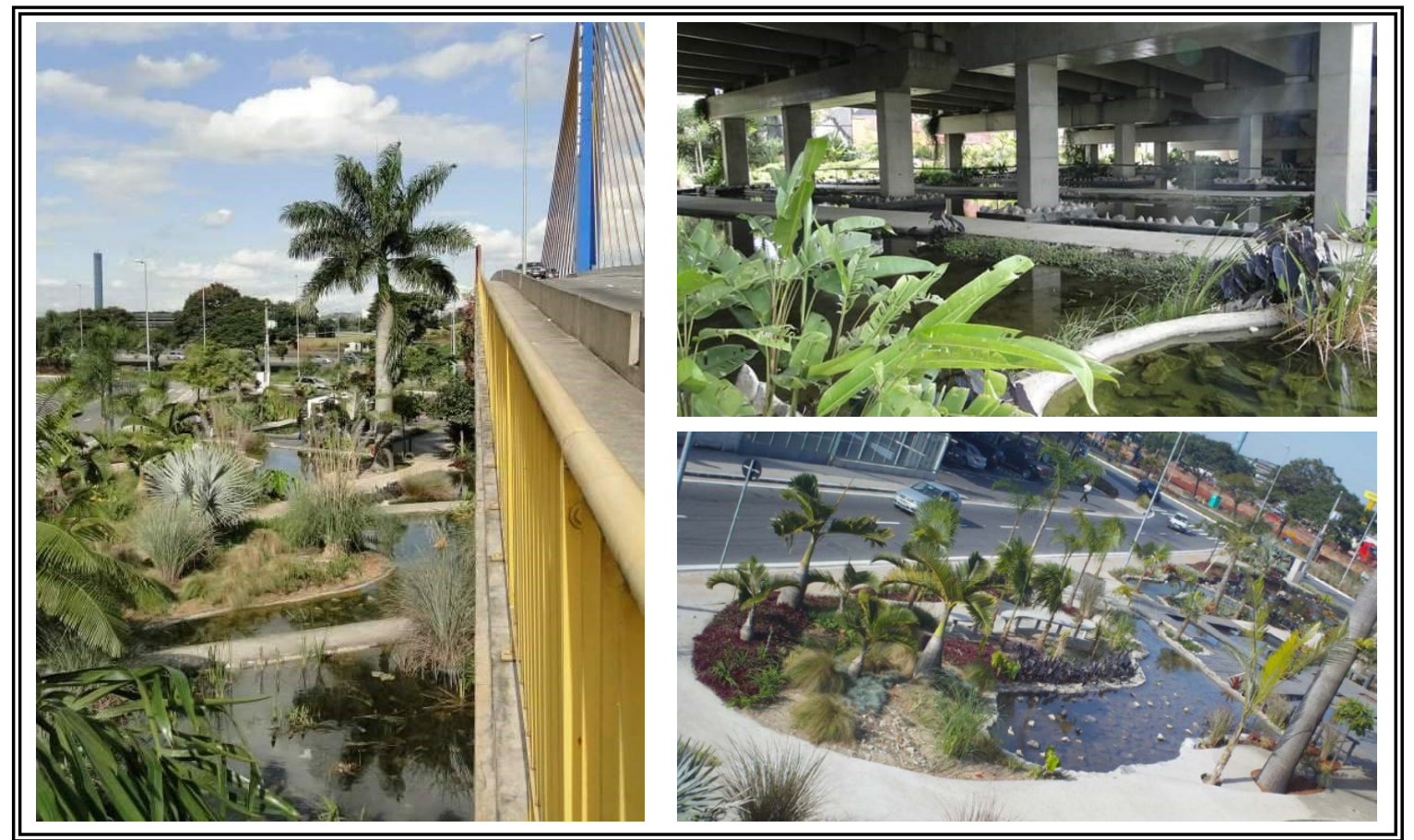

Fonte: AUTORA,2014. 


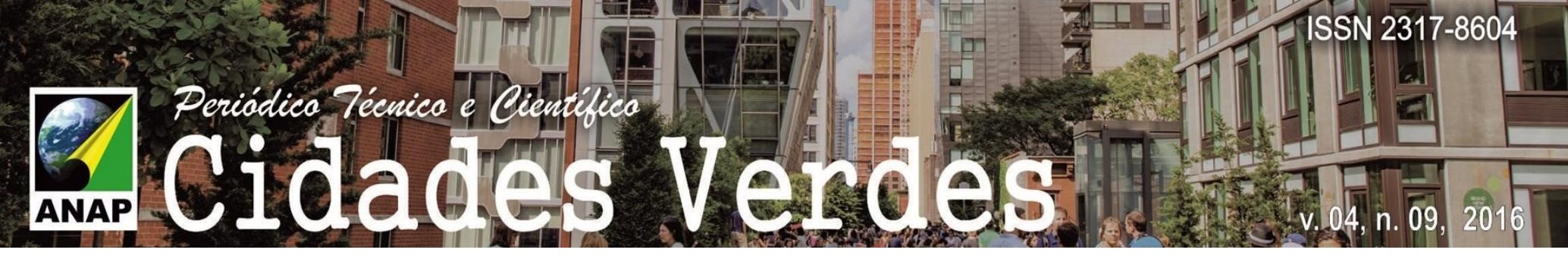

Projeto: Sistema BPP Viaduto - Sistema de bacias e pisos permeáveis em paisagismo no Viaduto "Cidade de Guarulhos".

Endereço: Av. Antonio de Souza, Macedo - Guarulhos, SP.

Área total de projeto: $9.000 \mathrm{~m}^{2}$

\section{Descrição:}

O projeto de paisagismo sob o Viaduto Cidade de Guarulhos possui 27 espelhos d água criados a partir da água proveniente de mina (por bombeamento) e também das águas pluviais captadas por parte do sistema de drenagem do viaduto. Os espelhos d'água são impermeabilizados - formando bacias de detenção - e interligados por tubos que conduzem a água por gravidade e possuem, ao final, um exutório para o sistema de drenagem convencional existente - galeria de águas pluviais sob a rua.

O Sistema BPP forma um conjunto de bacias de detenção com lâmina de água permanente, multifuncionais, combinadas com um projeto urbanístico de área verde com a valorização da presença da água no espaço urbano. As lâminas d'água possuem $30 \mathrm{~cm}$ de profundidade num traçado orgânico (sinuoso) como se fossem pequenos lagos. Além do bombeamento de água automático a cada $4 \mathrm{~h}$ da cisterna da mina de água, o que coopera para a circulação de água nos espelhos, todos possuem plantas aquáticas e peixes da espécie "guarus" (tamanho de 3 a $7 \mathrm{~cm}$ de comprimento) que objetivam melhorar a qualidade da água e evitar a proliferação de larvas de mosquitos transmissores de doenças.

Esses espelhos d'água também recebem água proveniente da rede de drenagem de um dos lados do viaduto, no qual foi aberto o fundo de uma das laterais da caixa da boca de lobo mais baixa e à montante dos espelhos d'água, que lançam as águas de chuva para o primeiro espelho d'água que possui maior quantidade de plantas macrófitas. Tais plantas, aquáticas possuem raízes que podem absorver grandes quantidades de substâncias tóxicas, além de formar uma densa rede capaz de reter partículas finas em suspensão, utilizadas com o intuito de melhorar a qualidade desta água escoada das vias.

As calçadas são permeáveis objetivando contribuir para aumentar a umidade do solo para os jardins laterais existentes ao longo dos passeios. 


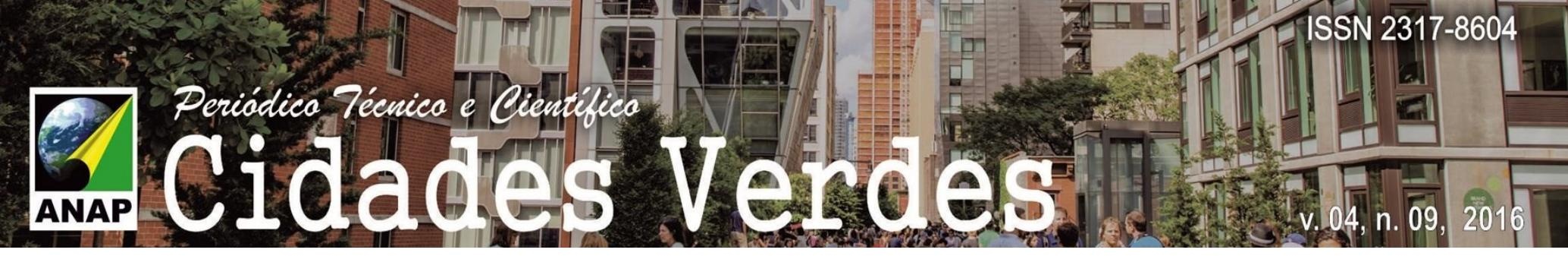

local. Foi constatado também que o usuário só percebe a vala quando ocorrem empoçamentos de água por um grande período, sendo imperceptível quando esta é apenas um canal gramado sinuoso no terreno. Os taludes e os morrotes modelados na lateral da VI criam também locais aparentemente convidativos param se sentar e assistir de um ponto mais elevado os jogos, propiciando uma "arquibancada" gramada. Tal afirmação se dá pela observação aos fins de semana, quando se dá o maior uso da área de lazer, onde muitos se sentam nestes pontos mais altos do talude da vala, para assistirem aos jogos de futebol, proporcionando a multifinalidade do espaço público.

O uso de vegetação mais arbustiva ao longo da vala compõe o paisagismo da área e é útil para "sinalizar" ao usuário a existência de taludes mais íngremes em certos pontos próximos ao passeio, proporcionando segurança e integração. Verificam-se que as plantas palustres nos pontos baixos da vala e nas pequenas bacias criam canteiros de jardins integrados ao conjunto. Desta maneira, a vegetação auxiliou a demarcar estes pontos baixos de retenção e infiltração de água de chuva na paisagem da área de lazer, valorizando a VI implantada.

\section{Análise 2 - DDI_ParCão}

Quanto à funcionalidade hidrológica, foi constatado no local que o sistema de TCs tem absorvido o impacto da velocidade da água da chuva escoada pelo sistema convencional de drenagem da via lindeira ao parque, pois não foram encontrados processos erosivos ao longo do sistema das técnicas, existente há 9 (nove) meses.

Porém, verificou-se que, após chuvas mais intensas, resíduos inorgânicos como papel, plásticos e metais trazidos pelas sarjetas da rua ficaram presos tanto nos poços quanto nas valetas, e que estes resíduos acabaram induzindo os usuários do parque a utilizarem os poços como locais de descarte de resíduos, ou seja, como "lixeiras".

Sob o ponto de vista da inserção urbana da T.C., foi verificado que na construção dos DDIs, o trabalho de dispor e encaixar os resíduos da construção civil ao longo das valetas, caixas d'água e sob as calçadas permeáveis, realizado quase que artesanalmente como se fossem pedras nos fundos e nas laterais do leito de um riacho, ajudou na percepção positiva pelos usuários. Devido à utilização de materiais reaproveitados que costumeiramente são descartados e pouco valorizados, foi constatado que o cuidado na estética de apresentação com auxílio da vegetação - e assentamento detalhado destes materiais, contribuiu para a valorização da aplicação das TCs com uso de materiais reaproveitados.

A vegetação escolhida e disposta em canteiros ao longo das valas, ao "pé" da sub-base dos passeios permeáveis, e em volta dos poços feitos com caixas d'água velhas, fez com que as técnicas ficassem inseridas nesta paisagem de forma mais natural, quando comparada com obras de concreto armado da drenagem convencional como escadarias hidráulicas, canaletas de concreto, etc.

Constatou-se que os materiais de reaproveitamento despertam o interesse e a curiosidade dos usuários sobre o modo de utilização e a funcionalidade dos mesmos no local. Dessa maneira, as TCs executadas nesse projeto obtiveram maior visibilidade, contribuindo para uma melhor compreensão do usuário sobre a questão da drenagem. 


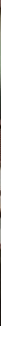

\section{Análise 3 - Sistema BPP_Viaduto}

Foi verificado que o conjunto de 27 (vinte e sete) espelhos d'água ornamentais interligados atende a função hidrológica de retenção de $945 \mathrm{~m}^{3}$ de água proveniente de mina captada sob equipamento público e de água pluvial captada por parte do sistema de drenagem do viaduto. Estas águas, lançadas nos espelhos $d$ água e armazenadas temporariamente, percorrem todo o sistema interligado de lagos que, ao exceder sua capacidade total, deságua na rede de drenagem convencional existente, por meio de um tubo de saída de PVC de $30 \mathrm{~cm}$ de diâmetro (vazão de restrição).

Quanto à função hidrológica do sistema BPP verificou-se que contribui para o amortecimento das inundações urbanas existentes a jusante do local, que se encontra próximo ao Canal de Circunvalação do Rio Tietê (área de várzea do Rio onde deságuam muitos córregos da cidade). Também verificou-se que contribuiu para a redução de sedimentos carreados antes de seu lançamento no curso d água e que, por fim, proporciona a valorização da presença da água no espaço urbano e beneficia o microclima através da evaporação de água que ameniza a temperatura local. $\mathrm{O}$ uso do concreto permeável, ainda não colmatado, garante umidade ao solo das plantas dos jardins lindeiros às calçadas.

Quanto à inserção urbana, verificou-se que a multifuncionalidade das bacias de detenção como espelhos d água ornamentais, transformou um espaço urbano normalmente degradado (área sob viaduto) em uma área verde contemplativa. Observa-se que os usuários do local caminham por entre os lagos observando peixes, plantas aquáticas, jardins e canteiros com diversas espécies de plantas constituindo-se em rara paisagem urbana. Dessa maneira afirmase que o foco do projeto urbanístico, as técnicas de drenagem, atenderam a função hidrológica e foram valorizadas pela ornamentação paisagística resultando num espaço urbano integrador. Foi verificado que tal espaço possui funcionários fixos da Secretaria de Meio Ambiente e Secretaria de Serviços Públicos do município que realizam uma constante manutenção na área. Evidencia-se a grande demanda de manutenção na limpeza (retirada) de resíduos descartados pela população nos espelhos d água. Por estar numa área bastante central - uma das principais entradas da cidade - funcionários relatam que usuários de drogas e moradores de rua que freqüentam o local, principalmente à noite, acabam provocando diversos danos e descartes de resíduos que acarretam uma necessidade de manutenção diária para que o local não tenha mau uso e gere problemas ambientais e sanitários.

\section{CONCLUSÃO}

As experiências realizadas em Guarulhos demonstraram que a implantação de TCs nos projetos de revitalização de áreas verdes urbanas contribuiu para trazer benefícios além da valorização da presença da água na paisagem, possibilitando soluções alternativas de baixo impacto na drenagem com capacidade de integrar-se à paisagem e em diversos usos urbanos. A variedade de aplicações das TCs utilizadas pela gestão publica mostrou que estas podem estar integradas de diversas maneiras, de acordo com a demanda do projeto, intervenção no local e com a disponibilidade de materiais. O intenso uso da vegetação e das técnicas aprimoradas de paisagismo foram responsáveis por demarcar as TCs na paisagem, 


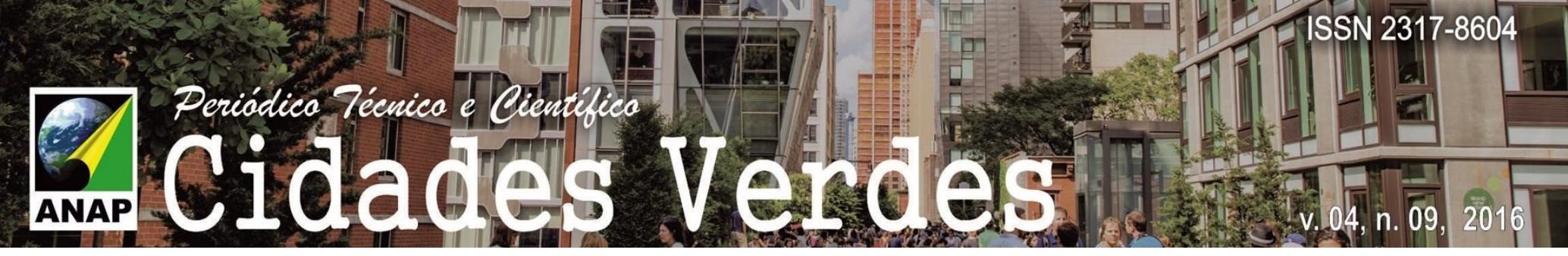

transformando-as no foco dos projetos e um importante elemento da composição urbanística. Tal fato proporciona aos usuários o reconhecimento das TCs na paisagem, mesmo que ainda não conhecidas pela sua função hidrológica, mas pelo seu apelo estético e de contemplação com as quais foram projetadas e executadas.

Pode-se considerar que as TCs realizadas estão cumprindo seu papel hidrológico e estão inseridas urbanisticamente, apesar da necessidade de aprimoramento, principalmente na avaliação prévia da capacidade de infiltração das águas - a fim de não se reter a água por mais de $24 \mathrm{~h}$ após as chuvas e na execução das técnicas para facilitar a infiltração (escarificação do solo, colocação de brita, etc).

Recomenda-se, portanto, maiores estudos e análises - já em andamento por meio de pesquisa em mestrado - para que estas e outras percepções sejam realmente identificadas e avaliadas quantitativamente a fim de aprimorar a aplicabilidade dessas TCs utilizadas pela administração pública de Guarulhos e que demonstram vantagens urbanísticas, econômicas e ambientais na solução dos problemas de drenagem tão comuns nas áreas urbanas.

\section{AGRADECIMENTO}

À Coordenação de Aperfeiçoamento de Pessoal de Nível Superior (CAPES), agência de fomento do Programa de Pós-graduação em Engenharia Urbana da Universidade Federal de São Carlos.

\section{REFERÊNCIAS BIBLIOGRÁFICAS}

BAPTISTA, M.; NASCIMENTO, N; BARRAUD, S. Técnicas Compensatórias em Drenagem Urbana. ABRH, Porto AlegreRS, 2011

GONÇALVES, L.M. ; BARBASSA, A.P. ; PEREIRA, T. R. D. S. El proyecto paisajístico como elemento integrador y identificador de técnicas compensatórias de drenaje. Congreso Internacional Towards Green Cities - Mérida, México. 2016

GUARULHOS (SP). Plano Diretor de Drenagem - Diretrizes, Orientações e Propostas. Prefeitura de Guarulhos. Guarulhos, São Paulo, 107p. 2008.

IBGE. Instituto Brasileiro de Geografia e Estatística. Censo Demográfico 2010.

TAVANTI, D.R. Desenvolvimento urbano de Baixo Impacto aplicado ao processo de planejamento urbano. Dissertação de Mestrado. São Carlos. UFSCar, 2009.

TUCCI, C. E. M., PORTO, R. L. L. BARROS, M. T. Drenagem urbana. ABRH/ UFRGS, Porto Alegre - RS, 1995. 